NISTIR 6913

\title{
Proposed Revisions of Part of the Test Procedures for Furnaces and Boilers in ASHRAE Standard 103-1993
}

Stanley T. Liu

U.S DEPARTMENT OF COMMERCE National Institute of Standard and Technology Building Environment Division Building and Fire Research Laboratory Gaithersburg, MD 20899-8631 


\section{Proposed Revisions of Part of the Test Procedures for Furnaces and Boilers in ASHRAE Standard 103-1993}

Stanley T. Liu

U.S DEPARTMENT OF COMMERCE National Institute of Standard and Technology Building Environment Division Building and Fire Research Laboratory Gaithersburg, MD 20899-8631

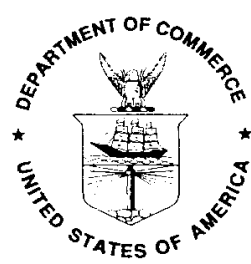

U.S. Department of Commerce Donald L. Evans, Secretary 
NISTIR 6913

\section{Proposed Revisions of Part of the Test Procedures for Furnaces and Boilers in ASHRAE Standard 103-1993}

Stanley T. Liu

U.S DEPARTMENT OF COMMERCE National Institute of Standard and Technology Building Environment Division Building and Fire Research Laboratory Gaithersburg, MD 20899-8631 



\section{Proposed Revisions of Part of the Test Procedures for Furnaces and Boilers in ASHRAE Standard 103-1993}

Stanley T. Liu

U.S DEPARTMENT OF COMMERCE National Institute of Standard and Technology Building Environment Division Building and Fire Research Laboratory Gaithersburg, MD 20899-8631

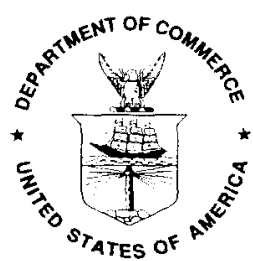

U.S. Department of Commerce Donald L. Evans, Secretary 



\title{
PROPOSED REVISIONS OF PART OF THE TEST PROCEDURES FOR FURNACES AND BOILERS IN ASHRAE STANDARD 103-1993
}

\begin{abstract}
$\underline{\text { ABSTRACT }}$
The U.S. Department of Energy's (DOE) procedure for testing the Annual Fuel Utilization Efficiency (AFUE) of residential central furnaces and boilers references ASHRAE Standard 1031993. The standard has been used by the furnaceboiler industry to obtain the AFUE values of their products as required by DOE. ASHRAE Standard Project Committee (SPC) 103R is in the process of making revisions to the standard to address some shortcomings and to improve the calculation procedure on the basis of comments and experiences from the industry. This report presents proposed revisions to certain part of the test procedure to address some of the comments. The proposed revisions include a new procedure to calculate the average burner on/off times of modulating furnaces/boilers during the cyclic operation of the burner, a revised method for the calculation of the annual burner operating hours, and an extension of the procedure to calculate the off-period flue loss of oil-tired equipment designed with a long post purge time. This report also provides the background information on the derivation of the integral functions listed in Appendix E of ASHRAE Standard 103-1993 that have not been formally documented. Those integral functions were used for producing the graphs in the standard for the hand calculation of the off-period losses with a calculator, and also in the numerical algorithm in the computerized calculation procedure.
\end{abstract}

Key words: Annual energy consumption, Annual Fuel Utilization Efficiency, ASHRAE standard 103, burner operating hours, central furnace and boiler, DOE test procedure, integral functions for off-period losses, step-modulating furnaceshoilers, two-stage furnaceshoilers 


\section{ACKNOWLEDGMENTS}

This study was sponsored by the U.S. Department of Energy, Office of Energy Efficiency and Renewable Energy.

\section{Use of Non-SI Units in a NIST publication}

The policy of the National Institute of Standards and Technology is to use the International System of Units (metric units) in all its publications. However, in North America in the construction and building materials industry, certain non-SI units are so widely used instead of SI units that it is more practical and less confusing to include measurement values for customary units only. 


\section{TABLE OF CONTENTS}

ABSTRACT

ACKNOWLEDGMENT

TABLE OF CONTENTS

iv

NOMENCLATURE

I. INTRODUCTION

2. ON/OFF TIMES FOR MODULATING FURNACEBOILER 2

2.1 Background

2.2 AFUE Calculated by Current Test Procedure

2.3 Review of Current Procedure for Single Stage Furnaces/Boilers

2.4 Proposed Procedure for Modulating Furnaces/Boilers

2.5 Examples of AFUE Calculated on the Basis of Proposed Procedure

3. ANNUAL BURNER OPERATING HOURS AND ANNUAL ENERGY CONSUMPTION OF MODULATING FURNACES AND BOILERS

3.1 Background

3.2 Review of Test Procedure for Single Stage Furnaces/Boilers

3.3 Proposed Procedure for Modulating Furnaces/Boilers

3.3.1 Annual Burner Operating Hours

3.3.2 Annual Fuel Energy Consumption

作

3.3.4 Units with Standing Pilot Light

4. CALCULATION OF OFF-PERIOD LOSSES FOR OIL-FIRED BOILERS WITH LONG POST PURGE TIME

4.1 Background

4.2 Calculation Procedure for Losses during Post Purge Period

4.2.1 Assumptions

4.2.2 Calculation for Sensible Loss

4.2.3 Calculation for Infiltration Loss

5. INFORMATION ON THE DERIVATION OF THE INTEGRAL FUNCTIONS

FOR CALCULATING THE OFF-PERIODLOSSES IN ASHRAE 103-1993

5.1 Background

5.2 Derivation of the Integral Functions 


\section{NOMENCLATURE}

XFUE

$\mathrm{A} / \mathrm{F}$

$\mathrm{BE}$

$\mathrm{BOH}$

$\mathrm{BOH}_{\mathrm{H}}$

$\mathrm{BOH}_{\mathrm{M}}$

$\mathrm{BOH}_{\mathrm{R}}$

$\mathrm{C}_{\mathrm{P}}$

$\mathrm{C}_{\text {T.OFF }}$

$D_{F}$

DHR

Dp

$E_{F}$

$E_{A E}$

Effy $_{\text {HS }}$

Effyss

Effy SS.M

F3, F4, F5

F6, F7, F8

$\mathrm{HHV}$

$\mathrm{HLH}$

$\mathrm{K}_{\text {S.OFF }}$

$\mathrm{L}_{\mathrm{I}, \mathrm{OFF}}$

$\mathrm{L}_{S, \mathrm{OFF}}$

$M_{\text {F.OFF }}$

$\mathrm{M}_{\mathrm{F} . \mathrm{ON}}$

$\mathrm{N}$

PE

QIN

QIN.H

QIN.R

Qout

Qout,M

QouT,R

QP

$\mathrm{t}$

$t_{p}$

$t_{\text {OFF }}$

toN

$\mathrm{T}_{\mathrm{C}}$

$T_{D}$

$T_{F . \text { OFF }}(t)$

$T_{F . S S}$ annual fuel utilization efficiency in percent

mass ratio of stoichiometric air to fuel

electrical power $(\mathrm{kW})$ to circulation air blower or water pump

number of annual burner operating hours

number of burner operating hours at maximum fuel input rate

number of burner operating hours at modulating fuel input mode

number of burner operating hours at reduced fuel input rate

specific heat of air

cool-down temperature profile correction factor for the effect of cycling

off-cycle draft factor for flue gas flow

design heating requirement

power burner draft factor

annual fuel energy consumption

annual electric energy consumption

heating seasonal efficiency in percent

steady-state efficiency in percent

average steady-state efficiency operating in modulating mode in percent

off-cycle sensible heat loss integration factors

higher heating value of fuel

heating load hours

multiplication factor for sensible heat loss during the off-period

off-cycle infiltration loss in percent

off-cycle sensible heat loss in percent

off-cycle flue gas mass flow rate (per minute)

on-cycle flue gas mass flow rate (per minute)

number of burner cycles per hour based on the response of thermostat at half load electrical power $(\mathrm{kW})$ to burner

steady-state rated (maximum) fuel input rate (per hour)

steady-state maximum fuel input rate (per hour) for a modulating unit

steady-state reduced (minimum) fuel input rate (per hour)

heating capacity, useful heat output per hour, under steady-state rated fuel input

average heat output rate (per hour) for modulating mode

heating capacity, at reduced (minimum) fuel input rate

fuel energy input per hour to pilot light

time in minute

power burner post-purge time period

burner off-time per cycle

burner on-time per cycle

balance point temperature for modulating units

design outdoor air temperature

off-period flue gas temperature at time $\mathrm{t}$

steady-state flue gas temperature 


$\begin{array}{ll}T_{O A} & \text { average outdoor air temperature } \\ T_{O A . H} & \text { average outdoor air temperature at maximum input operating mode } \\ T_{\text {OA.R }} & \text { average outdoor air temperature at reduced input operating mode } \\ T_{R A} & \text { laboratory room temperature } \\ T_{R E F} & \text { a reference air temperature } \\ V_{F, O F F} & \text { off-period flue gas volume flow rate in minute } \\ V_{F, O N} & \text { on-period flue gas volume flow rate in minute } \\ \mathrm{X} & \text { load factor, single-stage unit } \\ \mathrm{Xh} & \text { load factor when operating at maximum fuel input rate } \\ \mathrm{Xr} & \text { load factor when operating at reduced fuel input rate } \\ \mathrm{X}_{\mathrm{H}} & \text { fraction of heating load at maximum fuel input operating mode } \\ \mathrm{X}_{\mathrm{R}} & \text { fraction of heating load at reduced fuel input operating mode } \\ 1 & \text { ratio of circulation air blower or pump on-time to burner on-time } \\ a & \text { oversize factor, rated heating capacity to design heating requirement (DHR) } \\ \alpha_{R} & \text { oversize factor, heating capacity at reduced input rate to DHR } \\ \Delta t & \text { time interval } \\ \rho_{F} & \text { density of flue gas } \\ \tau_{\mathrm{OFF}} & \text { off-cycle time constant }\end{array}$





\section{INTRODUCTION}

The U.S. Department of Energy (DOE) test procedure ${ }^{[1]}$ for determining the Annual Fuel Utilization Efficiency (AFUE) of residential central furnaces and boilers referenced the industry test standard ANSI/ASHRAE 103-1993 ${ }^{[2]}$ (ASHRAE 103-1993) of the American Society of Hearing, Refrigerating, and Air Conditioning Engineers (ASHRAE). The standard was initially developed in 1982 based on the DOE test procedures for single stage furnaces and boilers recommended by Kelly et al ${ }^{[3]}$. It was subsequently revised in 1988 and again in 1993 to include test procedures for condensing units, modulating (or multi-fire) units, and for units employing a short post-purge period after the burner is shut off. In 1998 ASHRAE organized the Standard Project Committee (SPC) 103R to begin the revision process to ASHRAE 103-1993 following comments from the industry on the need to address some possible shortcomings of the standard based on user experiences. This report documents the proposals to SPC-103R to address the issues raised by industry concerning the test standard. The issues are as following:

(1) The inconsistency in the calculated AFUE values for a two-stage furnace (or boiler) when they are calculated on the basis of (a) the single-stage procedure and (b) the modulating two-stage procedure using the same test data. The first one treats the furnace as a single stage furnace operating at the reduced input to supply the heating load, and the second one treats the furnace as two-stage furnace. With a ratio of reduced input to rated input of from $60 \%$ to $70 \%$, the standard shows that the furnace would supply almost $98 \%$ of the annual heating load at the reduced input. That is, the furnace is operating as a single-stage furnace at the reduced fuel input rate most of the time even when it is treated as a two-stage furnace. However, the calculated results showed a difference in the AFUE values of more than one percentage point between the two procedures.

(2) In the calculation for the number of annual Burner Operating Hours (BOH) for a modulating furnace (or boiler), the standard estimates the $\mathrm{BOH}$ using the fuel and auxiliary electric energy input measured at the maximum rated input condition. For a two-stage furnace, the major portion of the heating load is supplied at the reduced input, with the auxiliary electrical components also operating under the settings for the reduced input rate.

(3) For units employing post purge after the burner is shut off, the standard provides a calculation procedure that limits the post purge time to three minutes. For some oil-fired boilers that require a longer post purge time, the formula in the standard will produce erroneous (smaller) flue loss result.

(4) The standard listed a group of integral functions named as F3 to F8 that were used to produce the graphs in the standard for hand calculation of the off-period losses, and in the numerical algorithm for the losses in a computerized calculation procedure. There is no documentation on the derivation of those functions. A search of the publications ${ }^{[3,4]}$ where the functions were first presented did not show the procedure or provide information about how the functions were derived. 
This report presents a proposed revision to the burner odoff times for a modulating appliance that corrected the inconsistency problem in AFUE, and a revised $\mathrm{BOH}$ calculation procedure for a modulating appliance that uses the measured fuel and auxiliary electric inputs at the actual operating conditions. The annual fuel and electric energy consumption are calculated on the basis of the $\mathrm{BOH}$. A procedure for the post purge calculation beyond three minutes is derived, and the background information of the process in the derivation of the integral functions F3 to F6 is shown.

\section{ON/OFF TIMES FOR MODULATING FURNACE/BOILER}

\subsection{Background}

The current test procedure in ASHRAE 103-1993 prescribes the calculation of the AFUE of a single stage furnace by using test data from the steady state, cool down and heat up tests at the rated input. In the calculation procedure, the average furnace cycling od off times are assumed to be $3.87 \mathrm{~min}$ on and $13.3 \mathrm{~min}$ off based on the characteristic responses of the room thermostat and a furnace oversize factor of 0.7 with respect to the building heating load. This results in the furnace operating at an average of $22.5 \%$ of the rated capacity during the heating season. The AFUE of a two-stage furnace is calculated by using test data from the steady state, cool down and heat up tests at both the maximum (high) input rate and at the minimum (low) input rate. There the average furnace cycling on/off time are assumed to be $10 \mathrm{~min}$ on and $10 \mathrm{~min}$ off. And this assumes the two-stage furnace operating at an average of $50 \%$ of the rated capacity during the heating season.

During the past years, a discrepancy in the calculation procedure was discovered with respect to some modulating furnaces. The AFUE value for the furnaces operating as a two-stage furnace was lower than the value when the same test data were used in a calculation with the furnace operating as a single stage furnace operating under low firing rate. These furnaces were noncondensing two-stage furnaces with a low fire to high fire ratio of 0.60 to 0.70 that are typical of two-stage furnaces. The difference in the AFUE values between the two calculations (modulating procedure versus single stage procedure) can be more than 1 percentage point. However, based on the test procedure, a two-stage furnace with a ratio of low to high firing rates of 0.65 would operate in the low firing rate to meet more than $95 \%$ of the annual heating load in a heating season. Therefore, the resulting AFUE was expected to be close to the value calculated on the basis of single-stage firing at the low rate over the entire heating season. The question was raised as to the reason for this one percentage point discrepancy in the AFUE values.

\subsection{AFUE Calculated by Current Test Procedure}

Using test data of a two-stage furnace, NIST investigated the cause of this discrepancy using the computer program AFUEBF (a computerized version of the calculation procedure of ASHRAE 103-1993). The original version and a slightly modified version of the program were run using the same test data as input. The modified version changed (only) the furnace on/off times to examine the effect of the changes in the on/off times. The changes made on the on/off times were (1) $3.87 / 13.3 \mathrm{~min}$ for both single stage and two-stage calculation, and (2)10/10 min for 
both single stage and two-stage calculation. It was found that the discrepancy in the AFUE described above was caused by the difference in the on/off times assigned to a single stage lurnace versus to a two-stage furnace. The following examples show the results (AFUE) of two gas-fired, two-stage non-condensing furnaces using test data from a manufacturer. Both have a low fire to high fire input ratio of 0.65 . The maximum input of Example 1 is $80000 \mathrm{Btu} / \mathrm{h}$. The maximum input of Example 2 is $60000 \mathrm{Btu} / \mathrm{h}$.

\begin{tabular}{|c|c|c|c|c|c|}
\hline \multirow[t]{2}{*}{ Example 1: } & \multicolumn{5}{|c|}{ AFUE Value } \\
\hline & Using Sing & Stage Calculation & Using Tw & age Calculc & \\
\hline $\begin{array}{l}\text { On/Off } \\
\text { Time* }\end{array}$ & High-Fire & Low-Fire & High-Fire & Low-Fire & $\begin{array}{c}\text { Weighted } \\
\text { Average }\end{array}$ \\
\hline $\begin{array}{l}3.87 / 13.3 \\
10.0 / 10.0\end{array}$ & $\begin{array}{l}82.64 \\
82.37\end{array}$ & $\begin{array}{l}81.99 \\
81.59\end{array}$ & $\begin{array}{l}82.10 \\
81.50\end{array}$ & $\begin{array}{l}81.85 \\
81.53\end{array}$ & $\begin{array}{l}81.85 \\
81.52\end{array}$ \\
\hline
\end{tabular}

*Note: Current on/off times are 3.87/13.3 min for single stage furnace, 10/10 min for two-stage furnace. Value in bold type indicates result by current procedure for modulating furnace.

Example 2: $\quad \underline{\text { AFUE Value }}$

\begin{tabular}{|c|c|c|c|c|c|}
\hline \multirow[b]{2}{*}{$\begin{array}{l}\text { On/Off } \\
\text { Time* }\end{array}$} & \multicolumn{2}{|c|}{ Using Single Stage Calculation } & \multicolumn{3}{|c|}{ Using Two-Stage Calculation } \\
\hline & High-Fire & Low-Fire & High-Fire & Low-Fire & $\begin{array}{c}\text { Weighted } \\
\text { Average }\end{array}$ \\
\hline $\begin{array}{l}3.87 / 13.3 \\
10.0 / 10.0\end{array}$ & $\begin{array}{l}82.32 \\
81.50\end{array}$ & $\begin{array}{l}81.31 \\
80.33\end{array}$ & $\begin{array}{l}81.79 \\
80.34\end{array}$ & $\begin{array}{l}81.35 \\
80.32\end{array}$ & $\begin{array}{l}81.35 \\
\mathbf{8 0 . 3 4}\end{array}$ \\
\hline
\end{tabular}

*Note: Current on/off times are $3.87 / 13.3 \mathrm{~min}$ for single stage furnace, $10 / 10 \mathrm{~min}$ for two-stage furnace. Value in bold type indicates result based on current procedure for modulating furnace.

Example I shows that the current calculation procedure for a two-stage furnace gives a lower AFUE value $(81.52 \%)$ than if the furnace were operating as a single stage furnace (where the on/off times are set at $3.87 / 13.3 \mathrm{~min}$ ) at either high or low firing rates (AFUE of $82.64 \%$ and $81.99 \%$, respectively). When the on/off times were changed to $10.0 / 10.0 \mathrm{~min}$ for the low-firing, single stage case, the calculated AFUE became $81.59 \%$ which is closer to the $81.52 \%$ for the weighted two-stage result at the same 10.0/10.0 on/off times. (From ASHRAE 103-1993, the weighting factor for the two-stage calculation is greater than 0.95 at low fire and less than 0.05 at high fire - that is, the two-stage furnace operated almost all under low fire to meet the annual heating load). The same close agreement happens if the on/off times are 3.87/13.3 min for both single and two-stage calculation $(81.99 \%$ under single stage low fire and $81.85 \%$ under two- 
stage). Example 2 is from test data of another (smaller capacity) furnace. The results of this example show that the discrepancy under the current calculation procedure could be 1 percentage point in favor of the single stage calculation.

As described above, the discrepancy in the results in the current calculation procedure is caused by the difference in the assigned on/off times for the two types (single stage versus modulating) of furnaces. A possible revision would be to change the assigned on/off times to some more appropriate values. The problem is to determine what should be the corrected on/off times for a modulating furnace, or a modulating boiler (where odoff time are specified as $15 / 15 \mathrm{~min}$ in the present procedure).

Section 2.3 describes the current procedures for determining od off times. Section 2.4 describes the proposed procedure for determining the on/off times for a modulating furnacehoiler based on its minimum (low-fire) to maximum (high-fire) capacity ratio.

\subsection{Review of Current Procedure for Single Stage Furnaces/Boilers}

In the development of the original test procedure for a single stage unit, the on and off times of a furnacehoiler are calculated by the following equations [3].

$$
\begin{aligned}
& t_{O N}=\frac{60 X}{4 N X(1-X)} \\
& t_{\text {OFF }}=\frac{60}{4 N X(I-X)}-t_{O N}
\end{aligned}
$$

where

$\mathrm{N}=$ number of burner cycles per hour based on the responses of thermostat at half load,

$$
=5 \text { for furnace }
$$

$=2$ for boiler

$\mathrm{X}$ is the load factor and is defined as:

$$
X=\frac{65-T_{O A}}{65-T_{D}} \frac{1}{1+\alpha}
$$

where

$\mathrm{T}_{\mathrm{OA}}=$ the average outdoor temperature. $\left(\mathrm{T}_{\mathrm{OA}}=42^{\circ} \mathrm{F}\right.$ in the test procedure)

$\mathrm{T}_{\mathrm{D}}=$ the outdoor design temperature. $\left(\mathrm{T}_{\mathrm{D}}=5^{\circ} \mathrm{F}\right.$ in the test procedure)

$\alpha=$ oversize factor $=0.7$ for a single stage unit

For a single stage unit, $X=0.225$, based on the values of $T_{O A}, T_{D}$, and $\boldsymbol{a}$ in the test procedure. This resulted in the values of $\mathrm{t}_{\mathrm{ON}} / \mathrm{t}_{\mathrm{OFF}}$ of $3.87 / 13.3 \mathrm{~min}$ as given in the test procedure. 


\subsection{Proposed Procedu for Modulating Furnaces/Boilers}

For a niodulating furnace or boiler, the current test procedure assumed a load factor of $\mathrm{X}=0.5$ which would give the on/off times of $6 / 6 \min (\mathrm{N}=5)$ for furnaces and $15 / 15 \min (\mathrm{N}=2)$ for boilers. However, the actual on/off times for furnaces in ASHRAE 103-1993 was set at 10/10 instead of 6/6. A detailed description and the rationale for the setting of ordoff times for modulating furnaces/boilers in the current test standard was presented in reference [5]. However, since a modulating furnace (or boiler) does not always have the specific minimum input rate that would result in $X=0.5$ when the unit is operating in the minimum input rate, the on/off times actually vary depending on the ratio of the minimum to maximum input rates.

For modulating furnaceshoilers, ASHRAE 103-1993 defined a balance point temperature $T_{C}$ as the change over temperature for the unit to switch from the minimum input rate to the modulating input or the maximum input rate. The balance point temperature is defined as the value of the outdoor temperature above which the modulating equipment is capable of providing the building heating load requirement at the minimum or low input rate. For outdoor temperature below the balance point temperature, the unit will switch to its modulating mode of operation for step-modulating units or to its maximum input rate for a two-stage unit. In ASHRAE 103-1993, The balance point temperature is calculated as,

$T_{C}=65-(60)(1+\alpha) \frac{Q_{\text {OUT } . R}}{Q_{\text {OUT }}}$

Where Qout, ${ }_{R} /$ Qout is the minimum to maximum capacity ratio of the modulating unit. $\mathbf{a}=0.7$ is the oversize factor at the maximum input rate of the modulating unit. It is seen that the value of $\mathrm{T}_{\mathrm{C}}$ depends on the ratio of the minimum to maximum capacity ratio. With $a=0.7$ and a capacity ratio of approximately $0.5884, \mathrm{~T}_{\mathrm{C}}$ would be equal to approximately $5^{\mathrm{O}} \mathrm{F}$, the average outdoor design temperature. This means that for a furnaceboiler with a capacity ratio of greater than or equal to 0.5884 , the furnacehoiler will operate in the minimum (low) firing rate for the entire heating season. For values of the capacity ratio less than $0.5884, \mathrm{~T}_{\mathrm{C}}$ would have a value of between $5^{\circ} \mathrm{F}$ and $65^{\circ} \mathrm{F}$. In this range, the modulating unit will operate in the low firing rate when the outdoor temperature is between $T_{C}$ and $65^{\circ} \mathrm{F}$. The unit will switch to the maximum (high) firing rate (two-stage control) or to the intermediate (step-up) firing rates (step-modulating control) when the outdoor temperature is between the design temperature of $5^{\circ} \mathrm{F}$ and $\mathrm{T}_{\mathrm{C}}$. ASHRAE 103-1993 provides graphs to determine the fractions of the annual heating load $X_{R}$ and $X_{H}$ (as functions of $T_{C}$ ) that will be supplied by the modulating equipment operating at the minimum (low) and the maximum (high) firing rates, respectively. The standard also gives the values of the average outdoor temperatures $T_{\mathrm{OA}, \mathrm{R}}$ (between $\mathrm{T}_{\mathrm{C}}$ and $65^{\circ} \mathrm{F}$ in low firing rate operation) and $\mathrm{T}_{\mathrm{OA} . \mathrm{H}}$ (between $5^{\circ} \mathrm{F}$ and $\mathrm{T}_{\mathrm{C}}$ in high firing rate operation), as function of $\mathrm{T}_{\mathrm{C}}$. These remperatures are equivalent to the $\mathrm{T}_{\mathrm{OA}}$ of $42^{\circ} \mathrm{F}$ for the single stage equipment.

For the values of the capacity ratio (low fire to high fire) greater than approximately 0.59 , the modulating furnacehoiler operates mostly in the low firing rate. If, as assumed, the oversize 
factor $a$ of the unit operating at the high firing rate is at 0.7 . an oversize factor $\alpha_{R}$ at the minimum firing rate with respect to the building design heating load can be defined as,

$1+\alpha_{R}=\frac{Q_{\text {out.R }}}{D H R}$

where,

$\alpha_{R}=$ the oversize factor at the reduced input rate,

DHR $=$ Design Heating Requirement.

As stated before, at the maximum firing rate, the oversize factor $a$ is defined as,

$1+\alpha=\frac{Q_{\text {OUT }}}{D H R}$

Combining the above two expressions results in,

$1+\alpha_{R}=(1+\alpha) \frac{Q_{O U T, R}}{Q_{O U T}}$

It was noted at the meetings of the multi-fire working group of ASHRAE SPC 103R that at the values of $a=0.7$ and Qout.R / QOut of approximately 0.59 , the unit is no longer oversized at the minimum firing rate $\left(\alpha_{R} \cong 0\right)$. Therefore, equation (2-5) holds for values of $a$ and the capacity ratio that give a value of $\alpha_{R}$ equal or greater than 0 .

With the calculated $\alpha_{R}$ from equation (2-5), equation (2-3) for the load factor $X$ can be used to calculate a load factor $X r$ at the minimum input and a load factor $X h$ at the maximum input rate, as,

$$
\begin{aligned}
& X r=\frac{65-T_{O A . R}}{65-T_{C}} \frac{1}{1+\alpha_{R}}, \quad\left(\alpha_{R} \geq 0 .\right) \\
& X h=\frac{65-T_{O A . H}}{65-T_{D}} \frac{1}{1+\alpha}
\end{aligned}
$$

It was noted at the meetings of the multi-fire working group of ASHRAE SPC 103R that the minimum outdoor temperature for the load factor $\boldsymbol{X r}$ is $T_{C}$, not the design temperature $T_{D}$, since $T_{C}$ is the limiting low outdoor temperature for the modulating unit to operate in low firing rate.

In ASHRAE 103-1993 only the on/off times based on the low firing rate is used in the calculation procedure. This is because that, for the majority of modulating units, the requirement of optimum fuel to air ratio under all firing rates results in the capacity ratio of low to high firing of from 0.4 to 0.7 . In this range, from $80 \%$ to $99 \%$ of the annual heating load are met by the 
modulating unit operating at low fire. Employing the same approach, equation (2-6), in place of equation (2-3), can be used to calculate the load factor $X$. The on/off times of equations (2-1) and (2-2) for the modulating unit can then be calculated based on the value of $X$ from equation (2-6).

The calculated ordoff times are then used in the calculating procedure for modulating furnaces or boilers. The following table shows the calculated on/off times for a modulating furnace (with $\mathrm{N}=5$ ) and a modulating boiler $(\mathrm{N}=2)$, at capacity ratios of 0.4 to 0.75 , where 0.75 is the highest ratio defined in ASHRAE 103-1993 for modulating units. The two columns in the table labeled " $(\mathrm{N}=3)$ " showed the values of $\mathrm{t}_{\mathrm{ON}}$ and $\mathrm{t}_{\mathrm{OFF}}$ for the case that the value of $\mathrm{N}$ is assumed to be 3 instead of 5 for modulating furnaces. The value $\mathrm{N}=3$ resulted from the approximation of the on/off of 10/10 for modulating furnaces in ASHRAE 103-1993:

\section{Modulated Furnace On/Off Times Based on Qout.R / Qesr}

\begin{tabular}{|c|c|c|c|c|c|c|c|c|c|c|c|c|}
\hline $\begin{array}{l}\text { Capacit } \\
\text { Ratio }\end{array}$ & $\begin{array}{c}\mathrm{T}_{\mathrm{C}} \\
{ }^{\mathrm{O}_{\mathrm{F}}}\end{array}$ & $1+\alpha_{R}$ & $\mathrm{~T}_{\mathrm{OA} . \mathrm{R}}{ }^{\mathrm{O}}$ & $\mathrm{T}_{\mathrm{OA}, \mathrm{H}^{*}} *$ & $\mathrm{X}_{\mathrm{R}}{ }^{*}$ & $\begin{array}{l}X=X r \\
\text { Load } \\
\text { Factor }\end{array}$ & $\begin{array}{c}\mathrm{t}_{\mathrm{ON}} \\
(\mathrm{min}) \\
(\mathrm{N}=\end{array}$ & $\begin{array}{l}t_{\mathrm{OFF}} \\
(\mathrm{min}) \\
=5)\end{array}$ & $\begin{array}{l}\mathrm{t}_{\mathrm{ON}} \\
(\mathrm{min}) \\
\quad(\mathrm{N}=\end{array}$ & $\begin{array}{l}\text { toFF }_{\mathrm{OF}} \\
(\mathrm{min})\end{array}$ & $\begin{array}{l}\mathrm{t}_{\mathrm{ON}} \\
(\mathrm{min}) \\
\quad(\mathrm{N}=\end{array}$ & $\begin{array}{l}\mathrm{t}_{\mathrm{OFF}} \\
(\mathrm{min}) \\
=2)\end{array}$ \\
\hline .40 & 24.2 & 1.0 & 43.5 & 19 & 0.83 & 0.527 & 6.34 & 5.69 & 10.57 & 9.49 & 15.85 & 14.23 \\
\hline 0.45 & 19.1 & 1.0 & 42.6 & 15 & 0.89 & 0.488 & 5.86 & 6.15 & 9.77 & 10.25 & 14.65 & 15.37 \\
\hline 0.50 & 14.0 & 1.0 & 41.8 & 11 & 0.94 & 0.455 & 5.50 & 6.59 & 9.17 & 10.99 & 13.76 & 16.49 \\
\hline 0.55 & 8.9 & 1.0 & 41.0 & 7.5 & 0.97 & 0.428 & 5.24 & 7.01 & 8.74 & 11.69 & 13.11 & 17.53 \\
\hline 0.60 & 5 & 1.02 & 40.7 & 5 & 0.99 & 0.397 & 4.98 & 7.56 & 8.29 & 12.59 & 12.44 & 18.89 \\
\hline 0.65 & 5. & 1.11 & 40.7 & 5 & 0.99 & 0.367 & 4.74 & 8.19 & 7.89 & 13.64 & 11.84 & 20.46 \\
\hline 0.70 & 5 & 1.19 & 40.7 & 5 & 0.99 & 0.340 & 4.55 & 8.81 & 7.58 & 14.69 & 11.37 & 22.04 \\
\hline 0.75 & 5 & 1.26 & 40.7 & 5 & 0.99 & 0.318 & 4.40 & 9.44 & 7.33 & 15.74 & 10.99 & 23.61 \\
\hline
\end{tabular}

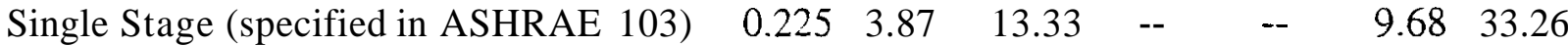

*Note: The values of $\mathrm{T}_{\mathrm{OA}, \mathrm{R}}$ (average outdoor temperature at minimum input), $\mathrm{T}_{\mathrm{OA}, \mathrm{H}}$ (average outdoor temperature at maximum input), and $X_{R}$ (the fraction of annual heating load supplied at the minimum input) as function of $T_{C}$ are from Figures 23 and 24 of ASHRAE 103-1993 ${ }^{\text {[2] }}$.

For comparison, the last row in the above table listed the values of the load factor $\mathrm{X}$ and the burner ordoff times for a single stage furnace (with $\mathrm{N}=5$ ) and a single stage boiler (with $\mathrm{N}=2$ ) as specified in ASHRAE 103-1993.

\subsection{Examples of AFUE Calculated on the Basis of Proposed Procedure}

The following are two examples of using the calculated on/off times (with $\mathrm{N}=5$ ) in the AFUE calculation for the two-stage furnace examples shown previously. In place of the fixed ordoff values of $10 / 10$ (minutes) for the furnace, the values were calculated using equations 2-1, 2-2, and 2-6) on the basis of the capacity ratio Qout, $\mathrm{R}$ /Qout. The capacity ratio was computed based on data from the steady states test. 
Example 1:

AFUE Value

\begin{tabular}{|c|c|c|c|c|c|}
\hline & \multicolumn{2}{|c|}{ Single Stage Calculation } & \multicolumn{3}{|c|}{ Two-Stage Calculation } \\
\hline On/Off & High-Fire & Low-Fire & High-Fire & Low-Fire & Weighted \\
\hline Times (min) & Test Data & Test Data & Test Data & Test Data & Average \\
\hline $3.87 / 13.3$ & 82.64 & 81.99 & & & \\
\hline $10.0 / 10.0$ & & & 81.50 & 81.53 & 81.52 \\
\hline \multicolumn{3}{|c|}{$+.59 / 8.67$ (Calculated) } & 81.90 & 81.70 & 81.71 \\
\hline
\end{tabular}

Example 2:

$\underline{\text { AFUE Value }}$

\begin{tabular}{|c|c|c|c|c|c|}
\hline \multirow{3}{*}{$\begin{array}{l}\text { On/Off } \\
\text { Times (min) }\end{array}$} & \multicolumn{2}{|c|}{ Single Stage Calculation } & \multicolumn{3}{|c|}{ Two-Stage Calculation } \\
\hline & High-Fire & Low-Fire & High-Fire & Low-Fire & Weighted \\
\hline & Test Data & Test Data & Test Data & Test Data & Average \\
\hline $3.87 / 13.3$ & 82.32 & 81.31 & & & \\
\hline $10.0 / 10.0$ & & & 80.34 & 80.32 & 80.34 \\
\hline $4.58 / 8.69(\mathrm{C}$ & ulated) & & 81.38 & 80.91 & 80.94 \\
\hline
\end{tabular}

In example 1, the calculated AFUE is $81.99 \%$ based on single-stage at low fire at the existing ordoff times, and $81.71 \%$ based on two-stage with the new ordoff times. For the second furnace, the comparison is $81.31 \%$ to $80.94 \%$. It is noted that even though the differences are smaller, the results still do not agree with each other exactly. This is because that for single-stage lowfire, the on/off times really should not be $3.87 / 13.3$ but instead should be approximately $4.6 / 8.7$ since at the low firing rate, the oversize factor is not 0.7 , but a smaller value of approximately $\alpha_{R}$ $=0.11$ (see previous table on the value of $\left(1+\alpha_{R}=1.11\right)$ at Qour.R / Qout of 0.65). If the odoff values of 4.6/8.7 are used in the single-stage calculation, the result would be very close to the two-stage procedure since in the two-stage operation, $99 \%$ of the annual heating load is met by the furnace operating under low-fire.

Lastly, it is noted that in the above proposal, the odoff times based on the low-fire condition are used for the high-fire portion of the calculation also. This is a simplification based on the reason that the fraction of high fire condition is small in the practical range of the capacity ratios from 0.40 to 0.75 . If more precision in the result is desired, separate load factors for $X h$ and $X r$ can be calculated from equations (2-6) and (2-7), and they in turn can be used to calculate the separate ordoff times for low fire and high fire conditions from equations (2-1) and (2-2). However, as stated before, it is considered at the present time to be not necessary for the range of capacity ratios encountered in practice. 


\section{ANNUAL BURNER OPERATING HOURS (BOH) AND ANNUAL ENERGY CONSUMPTION OF MODULATING FURNACES AND BOILERS}

\subsection{Background}

In the existing ASHRAE 103-1993/DOE test procedure ${ }^{[1.21}$, an equivalent number of burner operating hours $\left(\mathrm{BOH}_{\mathrm{SS}}\right)$ based on operation condition at the maximum rated input was defined to estimate the annual fuel energy consumption of both the single-stage and the modulating furnaces/boilers. For single stage units, the formulation is straightforward. The number of burner operating hours is calculated as the annual building load divided by the useful outputs of the furnaceboiler delivered to the conditioned space. The useful output energy from the furnacehoiler composed of the heat output from the burning of fuel at the heating seasonal efficiency plus the heat from the electrical power input to the auxiliary electric equipment. The annual fuel energy consumption is calculated as the number of burner operating hour times the rated energy input plus the off-period pilot light consumption if employed. For modulating furnacehoiler, the same formulation is retained. However, in the $\mathrm{BOH}_{S S}$ formula, a multiplication factor $\mathrm{R}=2.3$ or 3.0 (depending on the capacity ratio of minimum (low-fire) to maximum (high-fire)) is introduced in the auxiliary electrical power term. The heat energy output from the fuel is calculated as the maximum rated input at the weighted heating seasonal efficiency of the modulating furnaceboiler. The purpose of the factor $\mathrm{R}$ was to account for the greater on-time fraction per cycle $(0.50)$ for modulating unit as compared to the on-time fraction per cycle (0.225) for single stage unit. The ratio of 0.50 to 0.225 results in $R$ as 2.30 . The assumption was that the auxiliary electrical energy consumption of the modulating furnaceboiler due to the assumed larger fraction on time per cycle would be approximated by the multiplication factor 2.3 to the auxiliary electrical power input of air circulation blowers and power burners, etc. Since the maximum fuel input rate and the steady-state auxiliary electrical power input measured at the maximum firing rate are used to compute the $\mathrm{BOH}_{\mathrm{ss}}$, the term no longer represents the actual annual burner operating hours of the equipment which mostly operated in the reduced or modulating input mode. Rather, it is used as an equivalent $\mathrm{BOH}_{\mathrm{SS}}$ term to approximate or estimate the annual fuel energy consumption of the modulating equipment during a heating season. (Appendix C of ASHRAE 103-1993.) However, these assumptions ignored the effects of the possible different values of the electrical power input at the maximum and reduced fuel input rates for furnaceshoilers with a variable speed circulating air blower and combustion blower. Also, the use of the maximum fuel input rate in the calculation formula for the $\mathrm{BOH}_{\mathrm{SS}}$ causes confusion to users of the standard since for a modulating furnaceboiler, the design purpose is for the equipment to operate at the reduced input rate most of the heating season.

To improve upon the above-mentioned assumptions in the calculation procedure, the proposed calculation procedure would use the actual power inputs of a variable speed blower at the firing rates it is operating under. The actual burner operating hours at the maximum input and the reduced (minimum) input rates are calculated to determine the annual energy consumption of the equipment operating under both modes. The procedure would also use both the maximum and 
the reduced fuel input rates in the calculation of the burner operating hours under each firing rate to eliminate the approximation of an equivalent $\mathrm{BOH}_{\mathrm{SS}}$.

\subsection{Review of Test Procedure for Single Stage Furnaces/Boilers}

From Appendix A of NBSIR 78-1543 ${ }^{[3]}$ or Appendix C of ASHRAE 103-1993 ${ }^{[2]}$, the number of Burner Operating Hours $(\mathrm{BOH})$ and the annual fuel consumption $\mathrm{E}_{\mathrm{F}}$ for a single stage furnace are calculated as, for indoor installation,

$\mathrm{BOH}=\left[\right.$ Heating Season Fuel Consumed $-\left(\mathrm{Q}_{\mathrm{P}}\right)($ Heating Season Hour $\left.)\right] / \mathrm{Q}_{\mathbb{N}}$,

$E_{F}=$ Annual Fuel Energy Consumption

$=$ Heating Season Fuel Consumed $t\left(Q_{p}\right)$ (Non-Heating Season Hours),

Heating Season Fuel Consumed $=[$ Annual Building Load $-(\mathrm{PE}+\mathrm{y} \mathrm{BE})(\mathrm{BOH})] /$ Effy $_{\mathrm{HS}}$,

Annual Building Load $=(\mathrm{C})(\mathrm{HLH})(\mathrm{DHR}$,

where,

QIN = steady-state rated fuel energy input

$\mathrm{Qp}_{\mathrm{p}} \quad=$ pilot light fuel consumption rate

$\mathrm{BE} \quad=$ electric power to circulation blower or water pump

$\mathrm{PE} \quad=$ electric power to burner

$\mathrm{Y}=$ ratio of circulation blower or pump on-time to burner on-time in a burner cycle

Effy $_{\mathrm{HS}}=$ heating seasonal efficiency

HLH = Heating Load Hours

DHR = design heating requirement of a building

$\mathrm{C} \quad=0.77$, an adjustment factor defined in Appendix $\mathrm{C}$ of ASHRAE 103-1993.

For uniform rating purpose, ASHRAE 103-1993 established the following national average values for some of the weather-related parameters:

Non-Heating Season Hours $=4600$,

Heating Season Hours $=4160$,

Heating Load Hours $(\mathrm{HLH})=2080$.

For simplicity, let $\mathrm{Ep}=[(\mathrm{PE})+(\mathrm{y})(\mathrm{BE})], \eta_{\mathrm{u}}=\mathrm{Eff}_{\mathrm{HS}}$, and using the national average values,

$$
\begin{aligned}
\mathrm{BOH}= & \mathrm{HLH}[(\mathrm{C})(\mathrm{A})(\mathrm{DHR})-\mathrm{B}]=2080[(\mathrm{C})(\mathrm{A})(\mathrm{DHR})-\mathrm{B}], \\
& \mathrm{A}=1 /\left[\mathrm{Ep}+\left(\mathrm{Q}_{\mathrm{IN}}-\mathrm{Q}_{\mathrm{P}}\right) \eta_{\mathrm{u}}\right], \\
& \mathrm{B}=\left(\mathrm{Q}_{\mathrm{P}}\right)\left(\eta_{\mathrm{u}}\right)(\mathrm{A})(\text { Heating Season Hours }) / \mathrm{HLH}=2 \mathrm{Q}_{\mathrm{P}} \eta_{\mathrm{u}} \mathrm{A}
\end{aligned}
$$

The above equations are the same as those given in Appendix C of ASHRAE 103-1993, except that for simplicity, the percent and unit conversion factors ( 100 in percent and $3413 \mathrm{~W}=1 \mathrm{Btu} / \mathrm{h}$ ) spelled out in the equations in ASHRAE 103-1993 are not included here. (For use in actual 
calculation with numbers, consistency in units with the appropriate unit conversion factors is needed and included in the equations in the standard.)

\subsection{Proposed Procedure for Modulating Furnaces/Boilers}

\subsubsection{Annual Burner Operating Hours (BOH):}

The following nomenclature is used in the derivation of the proposed procedure:

$\mathrm{BOH}_{\mathrm{H}}=$ annual $\mathrm{BOH}$ of a two-stage unit at the maximum rated input $\mathrm{Q}_{\mathrm{IN}, \mathrm{H}}$

$\mathrm{Q}_{\mathrm{IN.H}}=$ fuel input rate at the maximum firing rate

$\mathrm{E}_{\mathrm{H}} \quad=$ electric power consumption measured under steady state at input $\mathrm{Q}_{\mathrm{IN} . \mathrm{H}}$

$\eta_{\mathrm{U}, \mathrm{H}} \quad=$ part-load efficiency of a two-stage unit operating at input $\mathrm{Q}_{\mathrm{N}, \mathrm{H}}$

$\mathrm{BOH}_{\mathrm{M}}=$ annual burner operating hours of a step-modulating unit at modulating mode

QIN.M $_{\text {I }}=$ fuel input rate in the modulating mode of a step-modulating unit as calculated in sec.1, Appendix C of ASHRAE 103-1993

$\mathrm{Ep}_{\mathrm{M}} \quad=$ electric power input of a step-modulating unit operating in the modulating mode and measured under steady state at input $\mathrm{Q}_{\mathbb{I N}, \mathrm{H}}$

$\eta_{u, M}=$ average part-load efficiency of a step-modulating furnacehoiler operating in the modulating mode (Sec. 11.4.9.2.3, ASHRAE 103-1993)

$\mathrm{BOH}_{\mathrm{R}}=$ annual burner operating hours at the minimum input $\mathrm{Q}_{\mathbb{N}, \mathrm{R}}$

$\mathrm{Q}_{\mathrm{IN}, \mathrm{R}}=$ fuel input rate at the minimum firing rate

$E_{p_{R}} \quad=$ electric power input measured under steady state at input $Q_{\mathbb{N} . R}$

$\eta_{\mathrm{u}, \mathrm{R}} \quad=$ part-load efficiency operating at input $\mathrm{Q}_{\mathrm{IN}, \mathrm{R}}$

It is assumed that for the modulating furnaceboiler operating at either the maximum or minimum input, or at modulating mode, the Design Heating Requirement (DHR) of the building is not changed and therefore the required furnaceboiler heat output to meet the DHR of the building is not changed.

For simplicity in showing the derivation process, it is assumed that the modulating unit has an electric ignition device so that the pilot $\mathrm{Q}_{\mathrm{P}}=0$ (extension of results to include $\mathrm{Q}_{\mathrm{P}}$ will be shown later in this report). With this assumption, the general equations for the $\mathrm{BOH}$ (Eq.3-1) and the variables $\mathbf{A}$ and $\mathbf{B}$ of Section 3.2 above are reduced to:

$\mathrm{B}=0$,

$\mathrm{A}=1 /\left[\mathrm{Ep}+\left(\mathrm{Q}_{\mathbb{N}}\right) \eta_{\mathrm{u}}\right]$

and

$\mathrm{BOH}=2080[(\mathrm{C})(\mathrm{A})(\mathrm{DHR})]$.

With the above assumptions, the burner operation hours in meeting the total annual heating load under the maximum firing rate is, 
$\mathrm{BOH}_{\mathrm{H}}{ }^{*}=\mathrm{HLH}\left[(\mathrm{C})\left(\mathrm{A}_{\mathrm{H}}\right)(\mathrm{DHR})\right]$,

$\mathrm{AH}_{\mathrm{H}}=1 /\left[\mathrm{Ep}_{\mathrm{H}}+\left(\mathrm{Q}_{\mathrm{IN} . \mathrm{H}}\right) \eta_{\mathrm{U}, \mathrm{H}}\right]$

where the asterisk * indicates the total $\mathrm{BOH}$ if the appliance operates at a particular (maximum here) firing rate for the entire heating season. If only a fraction of the total annual heating load is met by the appliance operating at the maximum firing rate, the actual $\mathrm{BOH}$ at the maximum firing rate (for a two-stage unit) during the heating season will be,

$\mathrm{BOH}_{\mathrm{H}}=\left(\mathrm{X}_{\mathrm{H}}\right)\left(\mathrm{BOH}_{\mathrm{H}}^{*}\right)=\left(\mathrm{X}_{\mathrm{H}}\right)\left[(\mathrm{C})(\mathrm{HLH})\left(\mathrm{A}_{\mathrm{H}}\right)(\mathrm{DHR})\right]$,

where $\mathrm{X}_{\mathrm{H}}$ is defined in Sec. 11.4.8.6 of ASHRAE 103-1993 as the fraction of the total annual heating load that is provided by a two-stage appliance at the maximum firing rate.

Similarly, the total burner operating hours to satisfy the total annual heating load when operating under the minimum firing rate for the entire heating season is,

$\mathrm{BOH}_{\mathrm{R}}{ }^{*}=\mathrm{HLH}\left[(\mathrm{C})\left(\mathrm{A}_{\mathrm{R}}\right)(\mathrm{DHR})\right]$,

$A_{R}=1 /\left[E_{p_{R}}+\left(Q_{\mathrm{IN}, R}\right) \eta_{\mathrm{U}, \mathrm{R}}\right]$.

And, if only a fraction of the total annual heating load is met by the appliance operating at the minimum firing rate, the $\mathrm{BOH}$ at the minimum firing rate during the heating season will be,

$\mathrm{BOH}_{\mathrm{R}}=\left(\mathrm{X}_{\mathrm{R}}\right)\left(\mathrm{BOH}_{\mathrm{R}}^{*}\right)=\left(\mathrm{X}_{\mathrm{R}}\right)\left[2080(\mathrm{C})\left(\mathrm{A}_{\mathrm{R}}\right)(\mathrm{DHR})\right]$,

where $X_{R}$ is defined in Ssc. 1 1.4.8.7 of ASHRAE 103-1993 as the fraction of the total annual heating load that is provided by a modulating appliance at the minimum firing rate.

For a step-modulating furnaceboiler, the fuel input rate at the modulating mode is not measured in ASHRAE 103-1993 since the firing rate at the modulating mode varies and cannot be determined a priori. Instead, ASHRAE 103-1993 calculates a Q IN.M $_{\text {as, }}$

Q $_{\text {IN,M }}=$ Qout,$M_{\text {M }} /$ Effyss,M $_{\text {, }}, \quad$ (From Sec. 1 of Appendix C, ASHRAE 103-1993)

where

EffysS,M $=$ average steady-state efficiency calculated in Sec. 11.4.8.8 of ASHRAE 103-1993

QouT.M = average heat output rate calculated in Sec. 11.4.8.10 of ASHRAE 103-1993

The fraction of the total annual heating load that is provided by a step-modulating appliance in the modulating mode, $X_{M}$, is assumed in ASHRAE 103-1993 to equal (1- $\left.X_{R}\right)$. That is, the modulating mode is at any input rate greater than the minimum input rate. Also, the electrical power inputs to the step-modulating appliance in the modulating mode $\left(\mathrm{BE}_{\mathrm{M}}\right.$ and $\left.\mathrm{PE}_{\mathrm{M}}\right)$ are not measured in ASHRAE 103-1993 and are assumed to be those measured during the steady-state test at the maximum fuel input rate, that is, $E p_{M}=E p_{H}$. Therefore, the burner operating hours for a step-modulating appliance operating in the modulating mode during the heating season is, 
$\mathrm{BOH}_{\mathrm{M}}=\left(\mathrm{X}_{\mathrm{H}}\right)\left[2080(\mathrm{C})\left(\mathrm{A}_{\mathrm{M}}\right)(\mathrm{DHR})\right]$,

where

$\mathrm{A}_{\mathrm{M}}=1 /\left[\mathrm{Ep}_{\mathrm{H}}+\left(\mathrm{Q}_{\mathrm{IN}, \mathrm{M}}\right) \eta_{\mathrm{U}, \mathrm{M}}\right]$

In the above formulation, the subscripts $\mathrm{H}, \mathrm{M}$ and $\mathrm{R}$ denote the values at the maximum firing rate, the modulating mode (step-modulating), and the minimum firing rate, respectively. The variables $E p_{H}, E_{p_{R}}, Q_{I N, H}, Q_{I N, R}, Q_{I N . M}, \eta_{U, H}, \eta_{U, R}$ and $\eta_{U, M}$ are defined previously.

\subsubsection{Annual Fuel Energy Consumption}

For two-stage modulating appliances, the annual heating load is met by the appliance operating at either the minimum firing rate or at the maximum firing rate. Therefore, the annual fuel energy consumption for a two-stage appliance is,

$\mathrm{E}_{\mathrm{F}}=\left(\mathrm{BOH}_{\mathrm{H}}\right)\left(\mathrm{Q}_{\mathrm{IN} . \mathrm{H}}\right)+(\mathrm{BOH} \mathrm{R})\left(\mathrm{Q}_{\mathrm{IN}, \mathrm{R}}\right)$

For step-modulating appliance, the total annual heating load is met by the appliance operating at either the minimum firing rate or at the modulating mode (up to the maximum firing rate). Therefore, the annual fuel energy consumption for a step-modulating appliance is,

$E_{F}=\left(B O H_{M}\right)\left(Q_{I N, M}\right)+\left(B O H_{R}\right)\left(Q_{I N, R}\right)$.

\subsubsection{Annual Auxiliary Electrical Energy Consumption}

The annual auxiliary electrical energy consumption for a two-stage appliance is,

$\mathrm{E}_{\mathrm{AE}}=\left(\mathrm{BOH}_{\mathrm{H}}\right)\left(\mathrm{E}_{\mathrm{PH}}\right)+\left(\mathrm{BOH}_{\mathrm{R}}\right)\left(\mathrm{Ep}_{\mathrm{R}}\right)$

The annual auxiliary electrical energy consumption for a step-modulating appliance is,

$E_{A E}=\left(B O H_{M}\right)\left(E_{p_{H}}\right)+\left(B O H_{R}\right)\left(E_{R}\right)$.

In the general form without the subscript, $\mathrm{Ep}=(\mathrm{BE})+(\mathrm{y})(\mathrm{PE})$, as defined previously.

\subsubsection{Units with Standing Pilot Light}

It is assumed previously that the modulating appliance employs interrupted electronic ignition and no pilot light is needed. If the modulating appliance has a continuing burning pilot light with fuel input rate $Q_{P}$, the above formulation should be modified by setting the parameters $A_{H}, A_{R}$, $\mathrm{A}_{\mathrm{M}}$ and $\mathrm{B}_{\mathrm{H}}, \mathrm{B}_{\mathrm{R}}, \mathrm{B}_{\mathrm{M}}$ as

$A_{\mathrm{H}}=1 /\left[\mathrm{Ep}_{\mathrm{H}}+\left(\mathrm{Q}_{\mathrm{IN}, \mathrm{H}}-\mathrm{QP}_{\mathrm{P}}\right) \eta_{\mathrm{U}, \mathrm{H}}\right]$,

$A_{R}=1 /\left[E_{R}+\left(Q_{\mathbb{N}, R}-Q_{p}\right) \eta_{U, R}\right]$, 


$$
\begin{aligned}
& A_{M}=1 /\left[E_{P_{H}}+\left(Q_{I N, M}-Q_{P}\right) \eta_{\mathrm{U}, \mathrm{M}}\right] \\
& \mathrm{B}_{\mathrm{H}}=2 \mathrm{Q}_{\mathrm{P}} \eta_{\mathrm{U}, \mathrm{H}} \mathrm{A}_{H} \\
& \mathrm{~B}_{\mathrm{R}}=2 \mathrm{Q}_{\mathrm{P}} \eta_{\mathrm{U}, \mathrm{R}} A_{\mathrm{R}} \\
& \mathrm{B}_{\mathrm{M}}=2 \mathrm{Q}_{\mathrm{P}} \eta_{\mathrm{U}, \mathrm{M}} \mathrm{A}_{\mathrm{M}}
\end{aligned}
$$

And the burner operation hours will be modified as

$$
\begin{aligned}
& \mathrm{BOH}_{H}=\left(\mathrm{X}_{\mathrm{H}}\right)(\mathrm{HLH})\left[(\mathrm{C})\left(\mathrm{A}_{\mathrm{H}}\right)(\mathrm{DHR})-\mathrm{B}_{\mathrm{H}}\right], \\
& \mathrm{BOH}_{\mathrm{R}}=\left(\mathrm{X}_{\mathrm{R}}\right)(\mathrm{HLH})\left[(\mathrm{C})\left(\mathrm{A}_{\mathrm{R}}\right)(\mathrm{DHR})-\mathrm{B}_{\mathrm{R}}\right], \\
& \mathrm{BOH}_{\mathrm{M}}=\left(\mathrm{X}_{\mathrm{H}}\right)(\mathrm{HLH})\left[(\mathrm{C})\left(\mathrm{A}_{\mathrm{M}}\right)(\mathrm{DHR})-\mathrm{B}_{\mathrm{M}}\right]
\end{aligned}
$$

The annual fuel energy consumption will be modified as,

For two-stage modulating appliance,

$$
E_{F}=\left(B O H_{H}\right)\left(Q_{I N, H}\right)+\left(B O H_{R}\right)\left(Q_{I N, R}\right)+\left[8760-\left(B_{H} H_{H}+B O H_{R}\right)\right] Q_{P}
$$

For step-modulating appliance,

$$
E_{F}=\left(B O H_{M}\right)\left(Q_{\mathbb{N} . M}\right)+\left(B O H_{R}\right)\left(Q_{\mathbb{N} . R}\right)+\left[8760-\left(B O H_{M}+B O H_{R}\right)\right] Q_{P}
$$

It is assumed that the value of $Q_{P}$ is the same for all modes of operations. The general equation forms of the parameters $\mathrm{A}$ and $\mathrm{B}$ and the $\mathrm{BOH}$ are shown in section 3.2 previously.

Note that the above formulation is for furnacehoiler installed indoors. For furnacehoiler installed in an unconditioned space as an isolated combustion installation or installed outdoors, the current DOE test procedure ${ }^{[1]}$ specified the procedure for modifying the calculation of the burner operating hours. The modification involved the accounting of the portions of the electric energy input to the blower motors that contribute to the heating of the conditioned space and the portions that are considered as lost to the ambient.

\section{CALCULATION OF OFF-PERIOD LOSSES FOR OIL-FIRED BOILERS WITH LONG POST PURGE TIME}

\subsection{Background}

As discussed previously, the post purge period in the test and calculation procedures of ASHRAE 103-1993 was limited to three minutes after the burner is shut off. This limit was considered adequate for most fossil-fueled appliances. However, for certain oil-fired boilers the operating requirement is such that the post purge period runs longer than three minutes. Since the longer post purge period resulted in greater off-period losses, it was deemed appropriate that calculation for the longer post purge period should be specified to account for the greater losses. 


\subsection{Calculation Procedure for Losses during Post Purge Period}

\subsubsection{Assumptions}

The following assumptions were made during the derivation of the post purge period losses in ASHRAE 103-1993. They are used in the present derivation also.

(a) Constant volumetric flue gas flow rate during post purge to equal to the on-cycle rate.

(b) Flue gas temperature approximated by piecewise linear variation over small time interval At.

(c) Measurement data of the flue gas temperature in the off-period, $T_{F . O F F}(t)$ at time interval At following burner shut-off.

\subsubsection{Calculation for Sensible Loss}

(a) Assuming constant combustion blower or draft inducer volumetric flow rate during the post purge period to equal the steady state on-period rate results in:

$V_{F, O N}=M_{F, O N} / \rho_{F, S S}=M_{F, \text { OFF }} / \rho_{F, \text { OFF }}=V_{F . \text { OFF }}$

where $V_{F, O N}$ and $M_{F, O N}$ are the volumetric and mass flow rate of the flue gas during the onperiod, respectively. $V_{F . O F F}$ is the off-period volumetric flow rate during post purge, and $\rho_{F, S S}$ and $\rho_{F, O F F}$ are the density of flue gas at temperatures $T_{F, S S}$ (steady state) and $T_{F . O F F}(t)$, respectively. $M_{F, O F F}(t)$ and $T_{F, O F F}(t)$ are the flue gas mass flow rate and temperature at time $t$ during the post purge period, respectively.

From the above equation, and assuming the flue gas as a perfect gas,

$M_{F, O F F}(t)=\frac{M_{F, O N} \rho_{F, \text { OFF }}}{\rho_{F . S S}}=\frac{M_{F, O N}\left(T_{F, S S}+460\right)}{\left(T_{F . U F F}+460\right)}$

(b) Assuming piecewise linear flue gas temperature variation over time interval $A t,\left(t, \leq t<t_{i+1}\right)$, during the post-purge period, gives

$T_{F, O F F}(t)=\left(T_{F, O F F, i} t_{i+1}-T_{F, O F F, i+1} t_{i}\right)\left(\frac{1}{\Delta t}\right)-\left(T_{F, O F F, i}-T_{F, O F F, i+1}\right)\left(\frac{1}{\Delta t}\right)(t)$

where $T_{F, O F F},=T_{F, O F F}\left(t_{i}\right)=$ flue gas temperature at time $t_{i}$ in post purge period.

Applying the factor $C_{T, \text { OFF }}$ for cycling effect to $\left(T_{F, O F F}(t)-T_{R A}\right)$ as in ASHRAE 103-1993:

$$
T_{F, O F F}(t)-T_{R A}=C_{T, O F F}\left\{\left[\left(T_{F, O F F, i^{i+1}}-T_{F, O F F, i+1} t_{i}\right)\left(\frac{1}{\Delta t}\right)-T_{R A}\right]-\left(T_{F, O F F, i}-T_{F, O F F, i+1}\right)\left(\frac{1}{\Delta t}\right)(t)\right\}
$$




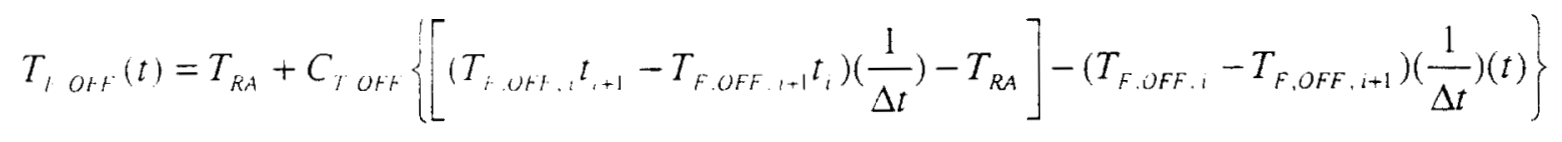

where $C_{\text {T.OFF }}=$ the cool-down temperature profile correction factor for the effect of cycling ${ }^{[1,2]}$

$\mathrm{T}_{\mathrm{RA}}=$ laboratory room air temperature.

The total sensible heat loss during the post-purge period is,

$$
\begin{aligned}
L_{S, \text { purge }} & =C_{P} \int_{0}^{t_{P}} M_{F, \text { OFF }}\left[T_{F, \text { OFF }}(t)-T_{R A}\right] d t \\
& =C_{P} M_{F, \text { ON }}\left(T_{F, S S}+460\right) \int_{0}^{t_{P}} \frac{T_{F, \text { OFF }}(t)-T_{R A}}{T_{F, \text { OFF }}(t)+460} d t \quad\left(\text { from equation }(4-2) \text { for } M_{F, \text { OFF }}\right) \\
& =C_{P} M_{F, \text { ON }}\left(T_{F, S S}+460\right) \sum_{i=1}^{N}\left[\int_{t_{i}}^{t_{1+1}} \frac{T_{F, \text { OFF }}(t)-T_{R A}}{T_{F, \text { OFF }}(t)+460} d t\right]
\end{aligned}
$$

where $t_{P}=$ total length of post purge time interval.

$\mathrm{N}=\mathrm{t}_{\mathrm{P}} / \mathrm{At}=$ number of intervals of length At within $\mathrm{t}_{\mathrm{P}}$

$C_{P}=$ specific heat capacity of flue gas

The percent sensible loss (as percent of total input during the on-cycle) during the post purge period is, by substituting the expressions for $\left(T_{F . O F F}(t)-T_{R A}\right)$ and $T_{F . O F F}(t)$ above into $L_{S \text {, purge, }}$ and integrate:

$$
\begin{aligned}
& L_{S, \text { OFF, purge }}=100 \frac{L_{S, \text { purge }}}{\left(Q_{I N}\right) t_{O N}} \\
& =100 \frac{C_{P} M_{F, O N}\left(T_{F, S S}+460\right) \Delta t}{\left(Q_{I N}\right) t_{O N}} \sum_{i=1}^{N}\left\{1-\frac{T_{R A}+460}{C_{T S}\left(T_{F, O F F, i}-T_{T F, O F F, i+1}\right)} \ln \left[\frac{T_{R A}+460+C_{T S}\left(T_{F, O F F, i}-T_{R A}\right)}{T_{R A}+460+C_{T S}\left(T_{F, O F F, i+1}-T_{R A}\right)}\right]\right\}
\end{aligned}
$$

where $C_{\mathrm{TS}}=\mathrm{C}_{\mathrm{T}, \mathrm{OFF}}$ for indoor combustion air,

$=C_{S}{ }^{\prime} C_{T, O F F}$ for outdoor combustion air,

$\mathrm{C}_{\mathrm{S}}{ }^{\prime}=$ off-period correction factor for outdoor unit as defined in ASHRAE 103-1993,

$t_{\mathrm{ON}}=$ burner on-time per cycle,

$\mathrm{Q}_{\mathrm{IN}}=$ fuel input rate.

$100=$ conversion factor from decimal to percent

\subsubsection{Calculation for Infiltration Loss}

The total infiltration hear loss, $L_{1, \text { purge }}$, during post purge period is, by the same way, 


$$
\begin{aligned}
L_{\text {l, purget }} & =C_{P} \int_{0}^{t_{p}} M_{F, \text { OFF }}\left[T_{R E F}-T_{O A}\right] d t \\
& =C_{P} M_{F, \text { ON }}\left(T_{F, S S}+460\right)\left(T_{R E F}-T_{O A}\right) \sum_{i=1}^{N}\left[\int_{i}^{t_{1}+1} \frac{1}{T_{F, \text { OFF }}(t)+460} d t \mid\right.
\end{aligned}
$$

where $T_{R E F}=a$ reference temperature defined to be $70^{\circ} \mathrm{F}$ in ASHRAE 103-1993,

$T_{O A}=$ heating season average outdoor temperature as defined in ASHRAE 103-1993.

The percent infiltration loss (as percent of total input during the on-cycle) during the post purge period Is. by substituting the expression for $T_{F, O F F}(t)$ in equation (4-3) into $L_{1}$. purge, and integrate:

$L_{l, \text { OFF }, \text { purge }}=100 \frac{L_{l, \text { purge }}}{\left(Q_{I N}\right) t_{\text {ON }}}$

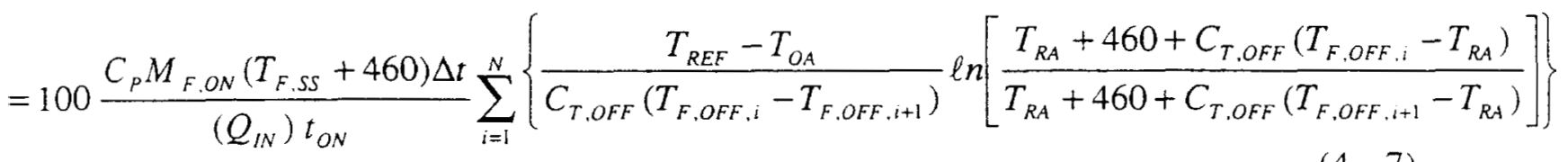

$(4-7)$

It is noted that when $\mathrm{N}=1 ; \mathrm{At}=\mathrm{t}_{\mathrm{p}}$, and the expressions for the sensible and infiltration losses during post purge reduce to the ones in ASHRAE 103-1993.

\section{BACKGROUND OF THE INTEGRAL FUNCTIONS FOR CALCULATING THE OFF-PERIOD LOSSES IN ASHRAE STANDARD 103-1993}

\subsection{Background}

In ASHRAE 103-1993, the off-cycle sensible and infiltration losses (see sections 11.2.10.6and 11.2.10.8 of the Standard) are calculated through the pair of functions (F3, F4); (F5, F6); or (F7, F8) depending on furnacehoiler location (indoor, outdoor, or isolated combustion system) and stack damper installation (with or without). The functions are presented in graphical forms (Figures 13 through 19 of the Standard) for manual calculation with an electronic calculator as well as in formula forms (in terms of definite integrals) presented in Appendix E of the standard. In the formulas for the functions F4, F6 and F8, there is a number 100 appearing as a divisor as well as an addition in the numerator and denominator of the first integral of each function (see Appendix E of ASHRAE 103-1993 for the exact locations). The same 100 also appears in the formula for the stack damper effectiveness factor $D_{O}$ and in the defining equations for the terms G3 and G4 in the formula for $D_{0}$ (see section 11.2.9.18 of ASHRAE 103-1993). In ASHRAE 103-1993 the term 100 was not defined. This brief report shows the origin of the term and the derivations of the integral functions.

\subsection{Derivation of the Integral Functions}


For illustration purpose, the following derivations use the case of a furnacehoiler using indoor air for combustion and installed indoors without a stack damper. The applicable function parr is $\mathrm{F} 3$ and $F 4$.

$$
\begin{aligned}
L_{S, O F F} & =\frac{(100)(0.24)\left(D_{F}\right)\left[1+\left(R_{T, F}\right)(A / F)\right]}{\left(H H V_{A}\right)\left(t_{\text {ON }}\right)} \frac{\left(T_{F . S S}-T_{R A}+530\right)^{1.19}}{\left(T_{F, S S}-T_{R A}\right)^{0.56}} \int_{0}^{t_{\text {OFF }}} \frac{\left(T_{F, \text { OFF }}-T_{R A}\right)^{1.56}}{\left(T_{F, \text { OFF }}-T_{R A}+530\right)^{1.19}} d t \\
& =\frac{K_{S, O F F}}{t_{\text {ON }}} \int_{0}^{t_{\text {OFF }}} \frac{\left(T_{F, \text { OFF }}-T_{R A}\right)^{1.56}}{\left(T_{F . O F F}-T_{R A}+530\right)^{1.19}} d t
\end{aligned}
$$

In Appendix A of the report NBSIR 78-1543 ${ }^{[3]}$, the off-cycle sensible heat loss is given as:

where

$$
\begin{aligned}
& \psi_{F, O}=\psi_{F . O . X} C_{t . O F F}=C_{t . O F F}\left[T_{F . O F F}\left(t_{3}\right)-T_{F . O F F}(\infty)\right] e^{t_{3} / \tau_{O H F}} \\
& \psi_{F, \infty}=T_{F . O F F}(\infty)-T_{R A},(t=\infty \text { denotes reaching equilibrium condition during off -period }) \\
& T_{F . O F F}(t)=\psi_{F .0} e^{-1} \tau_{O F F}+\psi_{F, \infty}+T_{R_{A}} \\
& \mathrm{t}_{3}=\text { a specific time in the off-period at which the flue gas temperature is measured, } \\
& \tau_{O F F}=\text { off-period time constant of the unit. }
\end{aligned}
$$

With the above defining equations for $\psi_{\mathrm{F}, 0}$ and $\psi_{\mathrm{F}, \infty}, L_{S \text {.OFF }}$ can be written as,

$$
L_{S, O F F}=\frac{K_{S, O F F}}{t_{O N}} \int_{0}^{I_{O F F}} \frac{\left(\psi_{F, 0} e^{-t / \tau_{O F F}}+\psi_{F, \infty}\right)^{1.56}}{\left(\psi_{F, 0} e^{-t / \tau_{O F F}}+\psi_{F, \infty}+530\right)^{1.19}} d t=\frac{K_{S, O F F}}{t_{O N}} \int_{0}^{t_{O F F}} F\left(t, \psi_{F, 0}, \psi_{F, \infty}\right) d t \quad(5-2)
$$

It is seen that in the above expression for $L_{S \text {.OFF }}$ is a function of $t$ with the $\psi_{F, 0}$ and $\psi_{F, \infty}$ as parameters whose values are determined from test data for a particular furnacehoiler.

During the 1970s when the furnace test procedure was developed, the accurate numerical evaluation of the integral in the above expression was a major problem without using a central computer. Therefore, it was decided that graphs would be developed to facilitate the calculation with the use of an electronic calculator. However, since both $\psi_{\mathrm{F}, 0}$ and $\psi_{\mathrm{F}, \infty}$ are related to a specific furnacehoiler and will have different values for different furnaceboiler, and a threedimensional graph with both as parameters on a graph was not practical, a large number of graphs would be required. That is, a number of graphs with $\psi_{\mathrm{F}, 0}$ as the parametric variable, similar to the two graphs for the functions F3 and F4 in ASHRAE 103-1993, would be needed for each value of $\psi_{F, \infty}$. One way to reduce the number of graphs required was to take the parameter $\psi_{F_{, \infty}}$ out of the integral. During the evaluation process, it was found that the function in the integral, $\mathrm{F}\left(\mathrm{t}, \psi_{\mathrm{F}, 0}, \psi_{\mathrm{F}, \infty}\right)$, can be approximated as a linear function of $\psi_{\mathrm{F}, \infty}$ for constant values of $t$ between 0 and $t_{\mathrm{OFF}}$ (13.3 min for furnaces and $33.3 \mathrm{~min}$ for boilers as assumed in the test procedure) and for constant $\psi_{F, 0}$. That is, it can be assumed that

$$
F\left(t, \psi_{F, 0}, \psi_{F, \infty}\right)=C_{1} \psi_{F, \infty}+C_{2}
$$


with the conditions $\mathrm{F}=\mathrm{F}\left(\mathrm{t}, \psi_{\mathrm{F}, 0}, 0\right)$ for $\psi_{\mathrm{F}, \infty}=0$; and $\mathrm{F}=\mathrm{F}\left(\mathrm{t}, \psi_{\mathrm{F}, 0}, 100\right)$ for $\psi_{\mathrm{F}, \infty}=100$, where the point $\psi_{F, \infty}=100$ was arbitrarily chosen as one possible value of off-cycle flue gas temperature (differential) at equilibrium. Usually, $\psi_{\mathrm{F}, \infty}=\mathrm{T}_{\mathrm{F}, \mathrm{OFF}}(\infty)-\mathrm{T}_{\mathrm{RA}}$ would be much smaller than 100. Figure 5-I shows a plot of the linear variation of the function $\mathrm{F}$ as a function of $\psi_{\mathrm{F}, \infty}$ between the values of 0 to 100 for ranges of $\mathrm{t}=0 \mathrm{~min}$ to $30 \mathrm{~min}$ after the burner was off for a boiler operating indoors with the value of $\psi_{\mathrm{F}, 0}$ determined by test data based on ASHRAE 103-1993. It is seen that the linear approximation is very good.

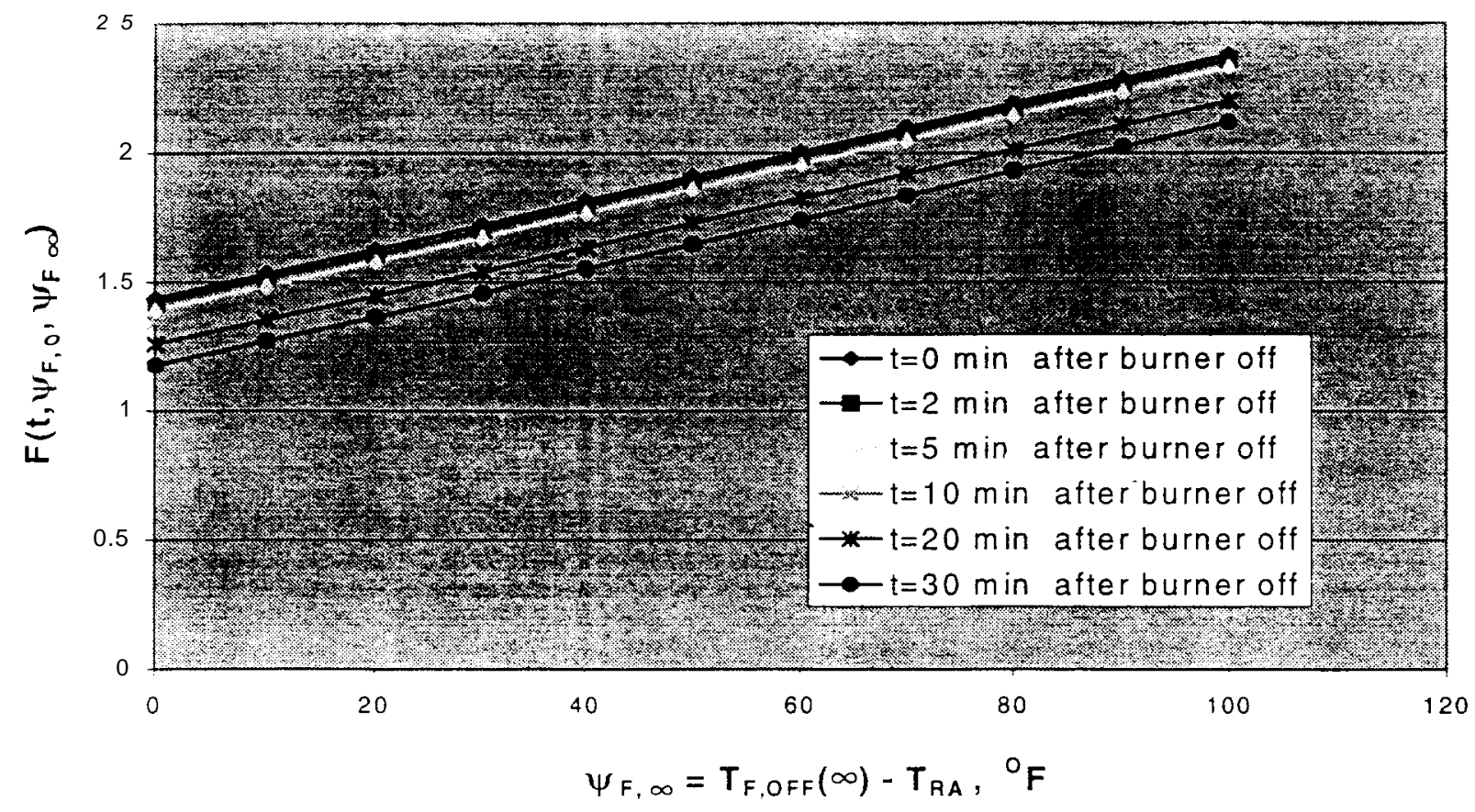

Figure 5-1 Variation of the function $F$ versus $\Psi_{F}, \infty$

With the above boundary conditions $\left(\mathrm{F}=\mathrm{F}\left(\mathrm{t}, \psi_{\mathrm{F}, 0}, 0\right)\right.$ for $\psi_{\mathrm{F}, \infty}=0$; and $\mathrm{F}=\mathrm{F}\left(\mathrm{t}, \psi_{\mathrm{F}, 0}, 100\right)$ for $\psi_{F, \infty}=100$ ), the functional form of $C_{1}$ and $C_{2}$ in the linear approximation can be determined as,

$C_{2}=F\left(t, \psi_{F, 0}, 0\right)$

$C_{l}=\left[F\left(t, \psi_{F, 0}, 100\right)-F\left(t, \psi_{F, 0}, 0\right)\right] / 100$

Or, explicitly,

$C_{2}\left(t, \psi_{F, 0}\right)=F\left(t, \psi_{F, 0}, 0\right)=\frac{\left(\psi_{F, 0} e^{-t / \tau_{, F F}}\right)^{1.56}}{\left(\psi_{F, 0} e^{-t / \tau_{\text {OFF }}}+530\right)^{1.19}}$ 


$$
\begin{aligned}
C_{1}\left(t, \psi_{F, 0}\right) & =\frac{1}{100}\left[F\left(t, \psi_{F, 0}, 100\right)-F\left(t, \psi_{F, 0}, 0\right)\right] \\
= & \left(\frac{1}{100}\right)\left[\frac{\left(\psi_{F, 0} e^{-t / \tau_{\text {OFF }}}+100\right)^{1.56}}{\left(\psi_{F, 0} e^{-t / \tau_{\text {OFF }}}+630\right)^{1.19}}-\frac{\left(\psi_{F, 0} e^{-t / \tau_{\text {OFF }}}\right)^{1.56}}{\left(\psi_{F, 0} e^{-t / \tau_{\text {OFF }}}+530\right)^{1.19}} \mid\right.
\end{aligned}
$$

Substituting the expressions of $\mathrm{C}_{1}$ and $\mathrm{C}_{2}$ into the function $\mathrm{F}$ inside the integral for the loss $\mathrm{L}_{\mathrm{S} \text {. OFF }}$ and changing the variable of integration from $t$ to $t / \tau_{\mathrm{OFF}}$, result in the expression for the approximation of $\mathrm{L}_{\mathrm{S} \text {.OFF }}$ by the functions $\mathrm{F} 3$ and F4 as shown in section 11.2.10.6 of ASHRAE 103-1993.

$$
\begin{aligned}
L_{S, O F F} & =\frac{K_{S, O F F}}{t_{O N}} \int_{O}^{t_{O F F}} F\left(t, \psi_{F, 0}, \psi_{F, \infty}\right) d t=\frac{K_{S, O F F}}{t_{\text {ON }}} \int_{0}^{t_{\text {IOF }}}\left[C_{2}\left(t, \psi_{F, 0}\right)+\psi_{F, \infty} C_{1}\left(t, \psi_{F, 0}\right)\right] d t \\
& =\left(K_{S, O F F}\right)\left(t_{O F F} / t_{O N}\right)\left[(F 3)+\left(\psi_{F, \infty}\right)(F 4)\right]
\end{aligned}
$$

where

$$
\begin{aligned}
& F 3\left(\psi_{F, 0}, t_{\text {OFF }} / \tau_{\text {OFF }}\right)=\frac{1}{t_{\text {OFF }} / \tau_{\text {OFF }}} \int_{0}^{t_{\text {OFF }} / \tau_{\text {OFF }}} \frac{\left(\psi_{F .0} e^{-t / \tau_{\text {OFF }}}\right)^{1.56}}{\left(\psi_{F, 0} e^{-t / \tau_{\text {OFF }}}+530\right)^{1.19}} d\left(t / \tau_{\text {OFF }}\right) \\
& F 4\left(\psi_{F .0}, t_{O F F} \text { "OFF }\right) \\
& =\frac{1}{100\left(t_{\text {OFF }} / \tau_{\text {OFF }}\right)} \int_{0}^{t_{\text {OFF }} / \tau_{\text {OFF }}}\left[\frac{\left(\psi_{F, 0} e^{-t / \tau_{\text {OFF }}}+100\right)^{1.56}}{\left(\psi_{F, 0} e^{-t / \tau_{\text {OFF }}}+630\right)^{1.19}}-\frac{\left(\psi_{F, 0} e^{-t / \tau_{\text {OFF }}}\right)^{1.56}}{\left(\psi_{F, 0} e^{-t / \tau_{\text {OFF }}}+530\right)^{1.19}}\right] d\left(t / \tau_{\text {OFF }}\right)
\end{aligned}
$$

It is noted that since the parameter $\psi_{F, \infty}$ is a constant, it is taken out of the integral involving F4 in the expression for $L_{S . O F F}$.

The function F5, F6, F7, and F8 in ASHRAE 103-1993 were derived the same way. It is noted here that in ASHRAE 103-1993, the derivation of the damper effectiveness factor $\mathrm{D}_{\mathrm{O}}$ and the defining equations for the terms G3 and G4 in the formula for $D_{O}$ (see section 11.2.9.18 of ASHRAE 103-1993) used the same approximation for the off-cycle losses (and the same term '100'). Details of that derivation is presented in the ASHRAE Transaction paper titled "The Effect of a Time Delayed Stack Damper on Off-Cycle Heat Losses for Residential Heating Equipment" by C. Park, et al. ${ }^{[6]}$

As mentioned before, the value 100 (as one possible temperature difference between the flue gas temperature and room temperature at equilibrium during cool down) was selected arbitrarily to determine the slope of the straight line in the linear approximation of the function $F\left(t, \psi_{F, 0}, \psi_{F, \infty}\right)$. For furnaces the actual temperature difference would be fairly small for unit with pilot light (and 
0 for unit with interrupted electronic ignition as specified in the test procedure), and for boilers the actual temperature difference would be generally much less than 100 .

\section{SUMMARY}

This report documented the developments of proposed revisions to the ASHRAE standard 1031993 on the method of testing for residential central furnaces and boilers. The changes include the following:

(1) A revised procedure to calculate the average burner on/off times of modulating furnaces and boilers during the cyclic operation of the burner. The procedure used the same cycles per hour at half load as were assumed for a single stage unit ( 5 cycles per hour for furnaces and 2 cycles per hour for boilers), thus gives a more consistent comparison with a single stage unit.

(2) A revised method for the calculation of the annual burner operating hours using the measured electric power input at the actual fuel input rate to determine the annual burner operating hours and the annual fuel and electric energy consumption at the actual burner firing rates of a modulating unit.

13) An extension of the current procedure to calculate the off-period flue loss of oil-fired equipment with a longer post purge time. The procedure will more accurately determine the offperiod flue loss that is higher when the boiler is operating with a longer than 3 min of post purge time.

This report also provides the background information on the derivation of the integral functions listed in Appendix E of ASHRAE standard 103-1993 that were not being formally documented. Those integral functions were used for producing the graphs in the standard for the hand calculation of the off-period losses with a calculator, and also in the numerical algorithm in the computerized calculation procedure. 


\section{REFERENCES}

I. Code of Federal Regulations, 10CFR Part 430, Subpart B, Appendix N, "Uniform Test Method for Measuring the Energy Consumption of Furnaces (May 1997)", January 1,2002

2. ANSYASHRAE standard 103-1993, "Methods of Testing for Annual Fuel Utilization Efficiency of Residential Central Furnaces and Boilers", ASHRAE, Atlanta, GA

3. Kelly, G.E., Chi, J., Kuklewicz, M.E., "Recommended Testing and Calculation Procedures for Determining the Seasonal Performance of Residential Central Furnaces and Boilers", NBSIR 78-1543, March 1978.

4. Chi. J.. Kelly, G.E., "A Method for Estimating the Seasonal Performance of Residential Gas and Oil-Fired Heating Systems", ASHR.AE Transactions, Vol. 84, Part 1, 1978

5. Kweller, E., "An Analysis of Burner On and Off Periods and Their Effect on Part-Load Efficiency for Furnaces and Boilers Equipped with modulating Controls", Letter Report prepared for the Department of Energy, January 1983

6. Park, C., Didion, D.A., Kelly, G.E., "The Effect of a Time Delayed Stack Damper on OffCycle Heat Losses for Residential Heating Equipment", ASHRAE Transactions, Vol. 89, 1983 